\title{
Characterization and prediction of tropical cyclone forerunner surge
}

\author{
Yi Liu' ${ }^{1}$, Jennifer L. Irish ${ }^{1}$
}

${ }^{1}$ Department of Civil and Environmental Engineering, Virginia Tech, Blacksburg, VA, USA

Corresponding author: Yi Liu (echoliu@vt.edu)

\section{Highlights:}

- Physical scaling laws are revealed to characterize forerunner surge from storm track

- The physical scaling enables rapid forecasting of forerunner surge.

\section{Abstract}

Forerunner surge, a water level rise ahead of tropical cyclone landfall, often strikes

11 coastal communities unexpectedly, stranding people and increasing loss of life. Surge forecasting

12 systems and emergency managers almost exclusively focus on peak surge, while much less

13 attention is given to forerunner surge. To address the need for fast and accurate forecasting of

14 forerunner surge, we analyze high-fidelity surge simulations in Virginia, New York/New Jersey

15 and Texas and extract physical scaling laws between readily available storm track information

16 and forerunner surge magnitude and timing. We demonstrate that a dimensionless relationship

17 between central-pressure scaled surge and wind-duration scaled time may effectively be used for

18 rapid forerunner surge forecasting, where uncertainty is considered. We use our method to

19 predict forerunner surge for Hurricanes Ike (2008) — a significant forerunner surge event—and

20 Harvey (2017). The predicted forerunner surge 24 to 6 hours before Hurricane Ike's landfall

21 ranged from 0.4 to $2.8 \mathrm{~m}$, where the observed forerunner surge ranged from 0.4 to $2.6 \mathrm{~m}$. This 
22 new method has the potential to be incorporated into real-time surge forecasting systems to aid

23 emergency management and evacuation decisions.

24 Keywords: Tropical cyclones; forerunner surge; modeling; forecasting; physical scaling;

25 ADCIRC.

26 


\section{Introduction}

Tropical cyclone (TC) storm surge has had devastating impacts on coastal communities worldwide, causing tremendous loss of life and physical damage. Peak surge is most often the

30 dominant driver of direct damage. Consequently, surge forecasting systems and emergency

31 managers have focused on improving prediction of peak surge, while less attention has been

32 given to forecasting forerunner surge - a storm-induced early water level rise above mean sea

33 level well in advance of TC landfall. The significance of forerunner surge was first observed in

34 1900, when Galveston, Texas was hit by a forerunner surge of $1.5 \mathrm{~m} 12$ hours prior to landfall

$35[1,2]$. This forerunner surge flooded essential roadways and stranded many people on Galveston

36 Island, directly contributing to the shocking death of 8,000 people, and making the 1900

37 Galveston Hurricane the deadliest hurricane on record [3]. Forerunner surge is most dangerous

38 for those who are in the direct path of the cyclone, where the forerunner surge precedes a high

39 peak surge. Significant forerunner surges occurred in 1900 and again in 2008 (Hurricane Ike)

40 when these storms made landfall in Galveston. Since 1900, forerunner surge on the order of 1 to

$412 \mathrm{~m}$ has been documented for TCs impacting both the US Gulf of Mexico and Atlantic coasts

42 (Table 1). Yet, while a few studies indicated that large TCs making landfall across a broad,

43 shallow continental shelf could potentially generate significant forerunner surges $[2,4]$ — where

44 Kennedy et al. demonstrated Hurricane Ike's large forerunner surge was predominantly from

45 Ekman setup (water level rise arising from the influence of Coriolis force)—we lack a basic

46 quantitative understanding of how and when significant forerunner surge is generated.

47 To better inform evacuation plans and thereby reduce loss of life, it is important to

48 understand the conditions in which a TC generates significant forerunner surge. Surge forecasts

49 historically focus on the rapid and accurate prediction of peak surge, and due to the need for 
50 rapid forecasting, either use a large ensemble set of track possibilities with low-fidelity surge

51 simulations (e.g., NOAA's P-Surge [5,6]), use a small, discrete set of storm track possibilities

52 with high-fidelity surge simulations (e.g., [7]), or use interpolation schemes to determine peak

53 surge from discrete, high-fidelity simulations for a large ensemble of track possibilities (e.g.,

$54[8,9])$. Some rapid surge prediction methods also consider forecasting of surge time series, where

55 either accuracy was compromised [7] or interpolation schemes were used [10]. Forerunner surge

56 is often overlooked when considering real-time forecasts.

57 Herein, to advance the physical understanding of forerunner surge generation and provide

58 a reliable and rapid forerunner surge forecasting method, we examine time series from high-

59 fidelity storm surge simulations for Galveston, TX, Hampton Roads, VA, and New York/New

60 Jersey, and we characterize forerunner surge magnitude and timing using physical scaling laws

61 based on storm track parameters.

\section{$62 \quad 2$ Methods}

63 The forerunner surge observational record is sparse, both in terms of the number of

64 cyclones observed and in spatiotemporal coverage, so we base our analysis on simulated wind,

65 barometric pressure, and surge for a range of synthetic TCs representative of observed storm

66 characteristics [11]. Here, the unstructured finite-element shallow water equations code ADCIRC

67 [12] is used, coupled with a spectral wave model (e.g., SWAN [13] or STWAVE [14]) to include

68 the effects of wave setup $[15,16]$. Runup from individual waves is not included. TC wind and

69 pressure fields are generated from a planetary boundary layer (PBL) model [17], using storm

70 track parameters as input, including storm position, central pressure deficit $(\Delta p)$ representing

71 intensity, radii to maximum wind $(R)$ representing storm size, forward speed $\left(V_{f}\right)$, heading $(\theta)$,

72 and profile parameter Holland B [18]. Our focus herein is on characterizing the forerunner surge 
73 anomaly (level above expected normal level). To simplify the analysis, astronomical tides are not

74 considered.

75 We conduct dimensional analysis on the simulations to find physical scaling laws relating

76 surge timing and magnitude to storm track parameters 12 to 24 hours before landfall. Former

77 studies have shown that the storm parameters most influencing the magnitude of peak surge are

78 landfall location $\left(x_{o}\right), \Delta p$, and $R$, while $V_{f}$ and $\theta$ have less impact [19]. In this forerunner surge

79 study we also focus on the storm parameters $\Delta p$ and $R$. However, we identify through sensitivity

80 analyses that $V_{f}$ also significantly influences forerunner surge, while heading and landfall

81 location have less impact. Specifically, while landfall location $\left(x_{0}\right)$ is known to strongly

82 influence peak surge [20], our sensitivity analysis indicates forerunner surge (represented by

83 surge 12 hours before landfall) is not very sensitive to moderate shifts in track, especially at the

84 open coast. At location TX-2 in Figure 1, as an example, our simulations exhibit differences in

85 forerunner surge magnitude 12 hours before landfall of less than $0.1 \mathrm{~m}$, when track spacing is

86 varied up to $35 \mathrm{~km}$, and when all other storm parameters are held constant. Field observations

87 also support this conclusion (see Appendix A, Figures A2-A7). When track is varied up to 200

$88 \mathrm{~km}$ to the south of Houston/Galveston (Figure A1), forerunner surge is generated, but its

89 magnitude does not change significantly, less than $0.2 \mathrm{~m}$. Storms tracking $100 \mathrm{~km}$ or more to the

90 north, northeast of Houston/Galveston do not generate forerunner surge; Houston/Galveston is

91 well to the left of the hurricane eyewall for these storms, which thus result in strong offshore

92 winds in the study area. A sensitivity test is also conducted in terms of storm heading $(\theta$,$) and$

93 results show little difference between storms with different headings (less than $0.1 \mathrm{~m}$ increase

94 over a heading change of \pm 45 degrees at location TX-2), although results in the bay can be more

95 complicated due to locally generated surge—a process not directly considered herein. 
Thus, for each region we consider just one heading, a limited range of $x_{o}$ (where

97 forerunner surge precedes a peak along-coast surge occurring near the study location), and a

98 wide range of $\Delta p, R$ and $V_{f}$.

99 We leverage existing surge simulations for Virginia and New York/New Jersey and

100 perform our own simulations for Texas. In Virginia and New York/New Jersey, we use the US

101 Army Corps of Engineers (USACE) STWAVE+ADCIRC simulations [21]. For this study, 19

102 synthetic TCs along three tracks making landfall in or near Hampton Roads are selected (Figure

103 1). All storms follow headings of $-60^{\circ}$ clockwise from north. Track parameters $\Delta p, R$, and $V_{f}$ are

104 respectively varied from 38 to $88 \mathrm{hPa}, 25$ to $109 \mathrm{~km}$, and 3.3 to $12.2 \mathrm{~m} / \mathrm{s}$ at landfall. Results are

105 shown for two representative locations near densely populated areas: Sewells Point (VA-1)

106 within Chesapeake Bay and Virginia Beach (VA-2) on the open coast. Similarly, 18 synthetic

107 TCs along three tracks in or near Sandy Hook, NJ are selected, with headings of -60o and track

108 parameters $\Delta \mathrm{p}, \mathrm{R}$, and Vf varying from 28 to $78 \mathrm{hPa}, 31$ to $139 \mathrm{~km}$, and 6.7 to $18.6 \mathrm{~m} / \mathrm{s}$ at

109 landfall. Results are shown for two representative locations near densely populated areas: The

110 Battery, NY (NJ-1) and Sandy Hook, NJ (NJ-2).

111 In Texas, we simulate surge using SWAN+ADCIRC, employing Dietrich et al.'s [16]

112 validated high-resolution computational mesh and model setup used in Kennedy et al.'s [2]

113 forerunner surge study. We first assess model performance using a synthetic TC similar to

114 Hurricane Ike in terms of these track parameters: $\Delta p$ of $63 \mathrm{hPa}, R$ of $74 \mathrm{~km}$, and $V_{f}$ of $18 \mathrm{~km} / \mathrm{h}$ at

115 landfall $[4,22]$. Wind and pressure forcing are developed using the PBL model. It should also be

116 noted that herein we define the forerunner surge generally as the water level rise ahead of TC

117 landfall, for the purposes of this paper the surge time series during the period from 24 to 6 hours

118 prior to landfall. With this definition, the forerunner surge encompasses Ekman setup as well as 
119 other processes inducing surge prior to landfall. This simulation is compared both with Kennedy

120 et al.'s [2] observations and simulation using the best available observation-based $\mathrm{H}^{*}$ Wind wind

121 field (Figure 2). Some differences exist between observations and our model results using

122 parameterized wind forcing, and most of these cannot be eliminated, even when using the

123 observation-based H*Wind forcing. Repeating Kennedy et al.'s analysis, our surge simulation

124 using parameterized winds when Coriolis force is disabled shows that the major part of Ike's

125 forerunner surge indeed does arise from Ekman setup, and is captured when using the

126 parameterized wind field. Note that the simulated surge time series herein do not show a

127 forerunner peak that is observed during Hurricane Ike, and we think this arises for two reasons.

128 First, although using a best wind field hindcast will certainly provide a more accurate simulated

129 estimate with a forerunner peak, we purposefully elect to use parameterized wind fields because

130 we want our results to be useful for forecasting purposes. Second, we hypothesize that the depth-

131 averaged model underestimates the current speed of importance to forerunner surge (that in the

132 upper ocean layer), thus underestimating the forerunner peak. This underestimate is also see in

133 the simulations using $\mathrm{H}^{*}$ Wind. Thus, although exhibiting some error, the synthetic storm surge

134 simulations analyzed herein can be used to assess trends in forerunner surge as a function of real-

135 time forecasted storm track parameters.

136 In Texas, we simulate surge for synthetic TCs along three tracks spaced $35 \mathrm{~km}$ apart and

137 making landfall in or near Galveston (Figure 1). All storms follow tracks oriented $-30^{\circ}$ clockwise

138 from north. Along the middle track (TX-T2), 42 combinations of $\Delta p, R$ and $V_{f}$ are simulated,

139 respectively spanning from 53 to $113 \mathrm{hPa}, 10$ to $85 \mathrm{~km}$, and 3 to $12 \mathrm{~m} / \mathrm{s}$ at landfall. These 42

140 simulations reveal trends consistent with those seen in the Virginia simulations, so a reduced set

141 of 19 TCs are simulated for the north (TX-T1) and south tracks (TX-T3). In all 80 unique storm 
142 simulations are considered in Galveston. Results are shown for two representative locations near

143 densely populated areas, Houston (TX-1) within Galveston Bay and Galveston (TX-2) on the

144 open coast. Selected storms are simulated without Coriolis forcing in order to confirm the

145 prominent role of Ekman setup in forerunner surge generation (Figure A8).

\section{Results and Discussion}

To identify the relative influence of each storm parameter on forerunner surge, we

148 investigate correlation between the forerunner surge magnitude and storm parameters. At 12

149 hours prior to landfall, for example, partial correlation coefficients for $\Delta p, R$, and $V_{f}$ are

150 respectively $0.52,0.82$, and -0.87 for Virginia, $0.71,0.86$, and -0.73 for Texas, and $0.56,0.68$,

151 and -0.83 for New York/New Jersey. As $\Delta p$ and $R$ increase, so do forerunner surge (shown

152 herein) and peak surge [19]. In contrast, while increasing $V_{f}$ tends to increase peak surge

153 somewhat [23], it serves to decrease forerunner surge magnitude. This result is expected

154 considering the physics of forerunner surge demonstrated in Kennedy et al. [2] that shows strong

155 wind-generated alongshore currents on the continental shelf produce Ekman setup $\left(\zeta_{E k}\right)$ under

156 the effect of Coriolis force. Approximated from the cross-shore momentum balance, Ekman

157 setup is:

158

$$
\zeta_{E k}=\int \frac{f U}{g} d x
$$

159 where $f$ is the Coriolis coefficient, $U$ is alongshore water current speed, $g$ is gravitational

160 acceleration, and $x$ is in the cross-shore direction. The factors controlling timing and magnitude

161 of forerunner surge are the alongshore-current speed and the cross-shore width of the current

162 (Eq. 1's integration limit). 
Figure 2 shows simulated surge time series, where each storm is colored based on the

164 dimensional parameter $\left(\frac{R}{V_{f}}\right)(\Delta p)$ to reflect the positive correlation with $\Delta p$ and $R$ and negative

165 correlation with $V_{f}$. Results show that for the parameter range simulated, the forerunner surge

166 magnitude ranges from 0.0 to 2.0 m between 24 and 6 hours before landfall, in both Virginia and

167 Texas. As expected, surge increases in magnitude closer to landfall. The results further show

168 larger $\left(\frac{R}{V_{f}}\right)(\Delta p)$ results in larger forerunner surge. The interpretation is twofold. First, $\left(\frac{R}{V_{f}}\right)$

169 represents the duration in which strong cyclonic winds persist over the continental shelf. The

170 longer the wind field lingers in this relatively shallow-depth region, the more time it has to fully

171 develop an alongshore water current. Second, $\Delta p$ represents overall wind-field intensity. All else

172 being equal, a more intense TC generates a more intense wind field, which in turn induces a

173 stronger alongshore current.

174 To take a step further, we use dimensional analysis to develop physical scaling laws

175 relating forerunner surge and storm track parameters near landfall. The forerunner surge

176 magnitude and timing are scaled by $\Delta p$ and $\left(\frac{R}{V_{f}}\right)$ respectively. A region-specific characteristic

177 intensity $\left(\Delta p_{\text {char }}\right)$ and characteristic duration $\left(t_{\text {char }}\right)$ are further integrated into the scaling to

178 account for regional characteristics. Thus,

179

$$
\left\{\begin{array}{l}
\zeta^{\prime}=\left(\frac{\gamma \zeta}{\Delta p}\right)\left(\frac{\Delta p_{\text {char }}}{\Delta p}\right)^{\alpha} \\
t^{\prime}=\left(\frac{t}{R / V_{f}}\right)\left(\frac{t_{\text {char }}}{R / V_{f}}\right)^{\alpha}
\end{array}\right.
$$

180 where $\gamma$ is the specific weight of seawater, $t$ is time before peak surge on the open coast, and $\zeta$ is

181 surge magnitude. The quantity $\left(\frac{\gamma \zeta}{\Delta p}\right)$ in Eq. 2a is derived from the momentum balance, where $\Delta p$

182 is considered proportional to surface wind stress in a quadratic form $\left(\Delta p \propto u_{\text {wind }}^{2}\right)[20,24]$, and 
183 the quantity $\left(\frac{\mathrm{t}}{\mathrm{R} / \mathrm{V}_{\mathrm{f}}}\right)$ in Eq. $2 \mathrm{~b}$ represents wind duration. The term $\Delta \mathrm{p}_{\text {char }}$ is regional mean

184 observed central pressure deficit, $58 \mathrm{hPa}$ in Virginia and New York/New Jersey, and $62 \mathrm{hPa}$ in

185 Texas. The term $t_{\text {char }}$ is defined as $\frac{L_{\text {shelf }}}{\sqrt{g \overline{h_{\text {shelf }}}}}$, where $L_{\text {shelf }}$ is reference continental shelf width,

186 taken as distance from the coastline to a depth of $100 \mathrm{~m}$, and $\overline{h_{\text {shelf }}}$ is reference shelf depth,

187 taken as $50 \mathrm{~m}$. The term $L_{\text {shelf }}$ represents the Ekman setup integration limit and $\sqrt{g \overline{h_{\text {shelf }}}}$

188 represents a characteristic speed of a free wave on the shelf. The best-fit coefficient $\alpha$ is site-

189 specific. Taken as 0 in Virginia, -0.35 in Texas, and -0.35 in New York/New Jersey, $\alpha$ is thought

190 to arise from the effect of a curved coastline on Ekman setup. Specifically, we hypothesize the

191 concave coastline curvatures of the Galveston and New York/New Jersey regions redirect and

192 confine the driving alongshore current, while, the Hampton Roads region's convex coastline

193 curvature has less influence on the alongshore current. After scaling, Eq.2a represents the

194 dimensionless surge $\left(\zeta^{\prime}\right)$ and Eq.2b represents the dimensionless timing $\left(t^{\prime}\right)$ of forerunner surge.

195 By plotting the time series in this dimensionless space in Figure 3, the surge simulations at each

196 location collapse into a hyperbolic curve. Thus,

$$
\zeta^{\prime}=\frac{a}{t^{\prime}+b}+c
$$

198 where $a, b$, and $c$ are site-specific curve fitting coefficients (Table A2) that we hypothesize are

199 related to local factors, such as continental shelf width, latitude, and bathymetry.

$200 \quad$ Uncertainty associated with this time-evolving surge response function (Eqs. 2-3) arises

201 from two primary sources. First, these equations are based on high-fidelity synthetic storm surge

202 simulations. Thus, uncertainties related to parameterization of the wind fields, surge, and wave

203 model assumptions, are carried into the scaling. Based on comparing observations and high- 
204 fidelity surge simulations for eight historical hurricanes (US Atlantic coast: Sandy [2012], Irene 205 [2011], Isabel [2003], Gloria [1985], Josephine [1984]; US Gulf of Mexico coast: Ike [2008], 206 Katrina [2005], and Rita [2005]) [25,26], this uncertainty is found to increase linearly as surge 207 magnitude increases (Figure 7). Second, uncertainty arises from the curve fitting process, and is 208 also found to scale linearly with surge magnitude (Figure 7). Thus, as a measure of uncertainty, 209 total standard deviation of the time-evolving surge response function $\left(\sigma_{t o t}\right)$ is:

$$
\left\{\begin{array}{l}
\sigma_{\text {tot }}^{2}=\sigma_{\text {model }}^{2}+\sigma_{\text {function }}^{2} \\
\sigma_{\text {model }}, \sigma_{\text {function }}=(k)(\zeta)+l
\end{array}\right.
$$

211 where $\sigma_{\text {model }}$ is the standard deviation of wind and surge simulations, $\sigma_{\text {function }}$ is the standard

212 deviation of surge prediction calculated by Eqs. 2-3 compared to the simulated results, $\zeta$ is 213 forerunner surge magnitude at different times, and $\mathrm{k}$ and $\mathrm{l}$ are linear regression coefficients.

214 Uncertainty in predicting the timing of forerunner arrival is also quantified as the average 215 prediction uncertainty for observed forerunner surges ranging from 0.3 to $2.0 \mathrm{~m}$ (Figure 8). With uncertainty considered, Eqs. 2-3 may be used to rapidly predict forerunner surge for 217 a specific storm, as well as to determine the likelihood of the occurrence of storms with potential 218 to generate significant forerunner surge. As an example, Figure 5-6 shows forerunner surge at 24, 219 18, 12, and 6 hours before landfall at Virginia Beach (VA-2), Sandy Hook (NJ-2), and Galveston 220 (TX-2), where surge is calculated as $\zeta$ in Figure 5 and $\zeta \pm \sigma_{\text {tot }}$ in Figure 6 using Eqs. 2-4.

221 Within the range of storm track parameters considered, a forerunner surge of $1 \mathrm{~m}$ or more 222 generally occurs earlier than 12 hours before landfall. Using track parameters (Table A1), we 223 predict that 12 hours before landfall, the forerunner surge at Virginia Beach is $0.4-0.9 \mathrm{~m}$ during 224 Hurricane Isabel (2003), which made landfall about $200 \mathrm{~km}$ to the south, and is consistent with 225 an observed value of $0.5 \mathrm{~m}$ at the Sewells Point NOAA station ([27]; Figure A3). Hurricane 226 Sandy (2012) made landfall about $100 \mathrm{~km}$ to the south of Sandy Hook, where we predict the 
227 forerunner surge 12 hours before landfall is $0.4-1.1 \mathrm{~m}$. The observed value here was $1.2 \mathrm{~m}$ ([27];

228 Figure A4). We hypothesize that the slight underestimation is due to the long hovering of

229 Sandy's enormous wind field on the continental shelf before it changed direction to make

230 landfall. In Galveston, we predict Hurricane Ike's (2008) forerunner surge 24, 18,12 and 6 hours

231 before landfall is $0.4-0.9 \mathrm{~m}, 0.5-1.1 \mathrm{~m}, 0.7-1.6 \mathrm{~m}$, and 1.2-2.8 $\mathrm{m}$, where observed value was

232 respectively $0.7 \mathrm{~m}, 1.1 \mathrm{~m}, 1.8 \mathrm{~m}$, and $2.6 \mathrm{~m}$ at the Galveston Pier 21 NOAA station ([2,27];

233 Figure A6). The predicted arrival for a 1.0-m forerunner during Ike is $14 \pm 7$ hours before landfall

234 (Figure S12, S13), where the observed arrival was 20 hours before landfall (Figure A6). Though

235 Hurricane Harvey's (2017) recent landfall was $250 \mathrm{~km}$ to the south of Galveston Pier 21, we

236 predict its forerunner surge 12 hours before landfall to be $0.4-0.9 \mathrm{~m}$, while the observed value

237 was $0.5 \mathrm{~m}$ (Figure A7). The arrival of a $0.5-\mathrm{m}$ forerunner during Harvey is predicted to be $15 \pm 7$

238 hours before landfall, while the observed was 18 hours before landfall (Figure A7).

239 These prediction-observation comparisons demonstrate that Eqs. 2-4 captures the

240 predominant physical mechanisms governing forerunner surge. The slight underestimation for

241 forerunner surge during Hurricane Ike at 18 and 12 hours before landfall is expected, considering

242 the employed hydrodynamic model underestimates surge for this event during this period. This

243 prediction could be more accurate with future hydrodynamic model improvements. The overall

244 uncertainty can be reduced with improved forecasting of the spatial wind field as well as with

245 improved operational forecast storm surge models.

246 Finally, we conduct extreme value analyses using Eqs. 2-4 and existing joint probability

247 statistics in Hampton Roads [28], New York/ New Jersey, and Galveston [29,8]. To estimate 1\%

248 annual exceedance probabilities (AEP) for forerunner surge, we employ the joint probability

249 method with optimal sampling (JPM-OS; [23]) achieved using time-evolving surge response 
250 functions of Eqs. 2 and 3. The joint probability density function is $f=$

$251 f(R \mid \Delta p) f\left(\Delta p \mid x_{o}\right) f\left(v_{f} \mid x_{o}\right) f\left(x_{o}\right)$. We use published parameterized probability density functions

252 for the U.S. Gulf of Mexico [8,29] and U.S. Atlantic [28] coasts to define $f(R \mid \Delta p), f\left(\Delta p \mid x_{o}\right)$,

$253 f\left(v_{f} \mid x_{o}\right)$, and $f\left(x_{o}\right)$, based on best available historical track information (e.g., [30,31]; A. Cox,

254 Oceanweather, Inc. personal communications). Only landfalling storms are considered, and

255 dependence on storm heading is neglected. We present uncertainty ranges based on our estimated

256 total standard deviation (Eq. 4). Results show that the 1\% annual exceedance probability (AEP)

257 forerunner surge 12 hours before landfall is $0.53 \pm 0.21 \mathrm{~m}$ at Virginia Beach, $0.71 \pm 0.31$ at

258 New York/ New Jersey, and $1.37 \pm 0.54 \mathrm{~m}$ at Galveston. This preliminary probabilistic hazard

259 assessment demonstrates the Houston-Galveston area is more prone to high forerunner surge,

260 compared with Hampton Roads and New York/ New Jersey, which is expected considering the

261 much wider and shallower continental shelf, generally lower bottom friction from the muddy

262 sediments along the Texas coast, and more frequent intense storms.

\section{Summary and Conclusions}

Forerunner surge in advance of TC landfall can leave people stranded, preventing

265 evacuation and rescue, thus leading to greater loss of life. With projected global sea level rise

266 and projected changes in storm climatology, forerunner surge is expected to play an even more

267 critical role in coastal hazards. Thus, it is of great importance to understand what storm

268 conditions have the potential to generate large forerunner surge, and to include prediction of

269 forerunner surge in public forecasts.

Our results confirm Ekman setup is the leading mechanism driving forerunner surge

271 generation in surge-prone regions characterized by broad, shallow terrain. We further

272 quantitatively prove that slow-moving, large, intense storms have the most potential for 
273 generating dangerous forerunner surge, because such storms generate and sustain the strong

274 alongshore currents needed to produce Ekman setup.

275 The physical scaling presented herein can be used to assess trends in forerunner surge as

276 a function of real-time forecasted storm track parameters only, allows identification of the range

277 of storm conditions in which a large forerunner surge is possible. The forecasting equations also

278 have the potential to be incorporated into coastal flooding warning systems, and may be used to

279 aid emergency managers and communities in evacuation planning and execution. Because the

280 predictive equations herein are physically based, they are also of high value to regions

281 worldwide influenced by TCs and surge threats, such as the Pacific coasts of southeast Asia,

282 west and east Australia [32], and the Bay of Bengal. In developing regions that lack sophisticated

283 computer modeling, the methods and findings can be applied directly to gauge data or limited

284 simulation results to better characterize forerunner surge threat.

285 While the TC climatology community has studied and come to consensus that future TCs

286 will be more intense under global warming [33,34], little attention has been given to the

287 influence of global warming on TC size and forward speed. Yet, such investigations are in

288 critical need given the significant influence of size and forward speed on forerunner surge.

289 Future work to improve understanding and ability to predict forerunner surge should

290 consider, for example, the influence of locally generated surge in coastal bays, tides, sea level

291 rise, and vertical flow structure (e.g, multi-layer hydrodynamic simulation) on Ekman setup.

\section{Acknowledgments}

293 This material is based upon work supported by the National Science Foundation under

294 Grant Nos. CMMI-1206271 and EAR-163009, and the Mid-Atlantic Coastal Storms Graduate

295 Research Fellowship (Project No. R/71858M). The work used resources of the Advanced 
296 Research Computing at Virginia Tech. The authors wish to thank the USACE for providing

297 surge simulation data, Oceanweather, Inc. for allowing use of their PBL Model, Drs. Casey

298 Dietrich and Joannes Westerink for providing the ADCIRC mesh and model setup used in Texas,

299 and Dr. Andrew Kennedy for providing his observational data from Hurricane Ike. The Texas

300 simulation data can be obtained in the supplemental material and the NACCS data is publicly

301 available online.

302 
304

305

306

307

308

309

310

311

312

313

314

315

316

317

318

319

320

321

322

323

324

325

326

327

328

329

330

331

332

333

334

335

336

337

338

339

340

341

342

343

344

345

346
[1] E.B. Garriott, West Indian hurricane of September 1-12, 1900, Mon. Weatther Rev. 28 (1900) 371-377.

[2] A.B. Kennedy, U. Gravois, B.C. Zachry, J.J. Westerink, M.E. Hope, J.C. Dietrich, M.D. Powell, A.T. Cox, R.A. Luettich, R.G. Dean, Origin of the Hurricane Ike forerunner surge, Geophys. Res. Lett. 38 (2011) L08608. doi:10.1029/2011GL047090.

[3] E.S. Blake, C.W. Landsea, E.J. Gibney, The deadliest, costliest, and most intense United States tropical cyclones from 1851 to 2010 (and other frequently requested hurricane facts), 2011. https://www.census.gov/history/pdf/nws-nhc-6.pdf.

[4] A. Sebastian, J. Proft, J.C. Dietrich, W. Du, P.B. Bedient, C.N. Dawson, Characterizing hurricane storm surge behavior in Galveston Bay using the SWAN + ADCIRC model, Coast. Eng. 88 (2014) 171-181. doi:10.1016/j.coastaleng.2014.03.002.

[5] A.A. Taylor, B. Glahn, Probabilistic guidance for hurricane storm surge, 19th Conf. Probab. Stat. 74 (2008).

[6] B. Glahn, A. Taylor, N. Kurkowski, W.A. Shaffer, The role of the SLOSH model in National Weather Service storm surge forecasting, Natl. Weather Dig. 33 (2009) 3-14.

[7] J.C. Dietrich, C.N. Dawson, J.M. Proft, M.T. Howard, G. Wells, J.G. Fleming, R.A. Luettich, J.J. Westerink, Z. Cobell, M. Vitse, H. Lander, B.O. Blanton, C.M. Szpilka, J.H. Atkinson, Real-Time Forecasting and Visualization of Hurricane Waves and Storm Surge Using SWAN+ADCIRC and FigureGen, in: Comput. Chall. Geosci., Springer, New York, NY, 2013: pp. 49-70. doi:10.1007/978-1-4614-7434-0_3.

[8] J.L. Irish, Y.K. Song, K.-A. Chang, Probabilistic hurricane surge forecasting using parameterized surge response functions, Geophys. Res. Lett. 38 (2011) L03606. doi:10.1029/2010GL046347.

[9] A.A. Taflanidis, A.B. Kennedy, J.J. Westerink, J. Smith, K.F. Cheung, M. Hope, S. Tanaka, Rapid assessment of wave and surge risk during landfalling hurricanes: probabilistic approach, J. Waterw. Port Coast. Ocean Eng. 139 (2013) 171-182.

[10] G. Jia, A.A. Taflanidis, N.C. Nadal-Caraballo, J.A. Melby, A.B. Kennedy, J.M. Smith, Surrogate modeling for peak or time-dependent storm surge prediction over an extended coastal region using an existing database of synthetic storms, Nat. Hazards. 81 (2016) 909938. doi:10.1007/s11069-015-2111-1.

[11] C.W. Landsea, D.A. Glenn, W. Bredemeyer, M. Chenoweth, R. Ellis, J. Gamache, L. Hufstetler, C. Mock, R. Perez, R. Prieto, J. Sánchez-Sesma, D. Thomas, L. Woolcock, A Reanalysis of the 1911-20 Atlantic Hurricane Database, J. Clim. 21 (2008) 2138-2168. doi:10.1175/2007JCLI1119.1.

[12] R.A. Luettich, J.J. Westerink, N.W. Scheffner, ADCIRC: An Advanced Three-Dimensional Circulation Model for Shelves, Coasts, and Estuaries. Report 1. Theory and Methodology of ADCIRC-2DDI and ADCIRC-3DL. No. CERC-TR-DRP-92-6., COASTAL ENGINEERING RESEARCH CENTER VICKSBURG MS, 1992.

[13] N. Booij, L.H. Holthuijsen, R.C. Ris, The "SWAN" wave model for shallow water, Coast. Eng. Proc. 1 (1996). https://journals.tdl.org/icce/index.php/icce/article/view/5257 (accessed November 8, 2016).

[14] J.M. Smith, A.R. Sherlock, D.T. Resio, STWAVE: Steady-State Spectral Wave Model User's Manual for STWAVE, Version 3.0, 2001. 
[15] J.C. Dietrich, Development and application of coupled hurricane wave and surge models for southern Louisiana, UNIVERSITY OF NOTRE DAME, 2011. http://gradworks.umi.com/34/36/3436250.html (accessed November 22, 2016).

[16] J.C. Dietrich, S. Tanaka, J.J. Westerink, C.N. Dawson, R.A. Luettich, M. Zijlema, L.H. Holthuijsen, J.M. Smith, L.G. Westerink, H.J. Westerink, Performance of the UnstructuredMesh, SWAN+ADCIRC Model in Computing Hurricane Waves and Surge, J. Sci. Comput. 52 (2012) 468-497. doi:10.1007/s10915-011-9555-6.

[17] E.F. Thompson, V.J. Cardone, Practical Modeling of Hurricane Surface Wind Fields, J. Waterw. Port Coast. Ocean Eng. 122 (1996) 195-205. doi:10.1061/(ASCE)0733950X(1996)122:4(195).

[18] G.J. Holland, An Analytic Model of the Wind and Pressure Profiles in Hurricanes, Mon. Weather Rev. 108 (1980) 1212-1218. doi:10.1175/15200493(1980)108<1212:AAMOTW>2.0.CO;2.

[19] J.L. Irish, D.T. Resio, J.J. Ratcliff, The Influence of Storm Size on Hurricane Surge, J. Phys. Oceanogr. 38 (2008) 2003-2013. doi:10.1175/2008JPO3727.1.

[20] J.L. Irish, D.T. Resio, M.A. Cialone, A surge response function approach to coastal hazard assessment. Part 2: Quantification of spatial attributes of response functions, Nat. Hazards. 51 (2009) 183-205. doi:10.1007/s11069-009-9381-4.

[21] Cialone, A.S. Grzegorzewski, D.J. Mark, M.A. Bryant, T.C. Massey, Coastal-Storm Model Development and Water-Level Validation for the North Atlantic Coast Comprehensive Study, J. Waterw. Port Coast. Ocean Eng. 143 (2017) 04017031. doi:10.1061/(ASCE)WW.1943-5460.0000408.

[22] R. Berg, Tropical cyclone report: Hurricane Ike 1-14 September 2008, National Hurricane Center, 2009.

[23] D.T. Resio, J. Irish, M. Cialone, A surge response function approach to coastal hazard assessment - part 1: basic concepts, Nat. Hazards. 51 (2009) 163-182. doi:10.1007/s11069009-9379-y.

[24] J.L. Irish, D.T. Resio, Method for Estimating Future Hurricane Flood Probabilities and Associated Uncertainty, J. Waterw. Port Coast. Ocean Eng. 139 (2013) 126-134. doi:10.1061/(ASCE)WW.1943-5460.0000157.

[25] S. Bunya, J.C. Dietrich, J.J. Westerink, B.A. Ebersole, J.M. Smith, J.H. Atkinson, R. Jensen, D.T. Resio, R.A. Luettich, C. Dawson, V.J. Cardone, A.T. Cox, M.D. Powell, H.J. Westerink, H.J. Roberts, A High-Resolution Coupled Riverine Flow, Tide, Wind, Wind Wave, and Storm Surge Model for Southern Louisiana and Mississippi. Part I: Model Development and Validation, Mon. Weather Rev. 138 (2010) 345-377. doi:10.1175/2009MWR2906.1.

[26] M.A. Cialone, T.C. Massey, M.E. Anderson, A.S. Grzegorzewski, R.E. Jensen, A. Cialone, D.J. Mark, K.C. Pevey, B.L. Gunkel, T.O. McAlpin, North Atlantic Coast Comprehensive Study (NACCS) Coastal Storm Model Simulations: Waves and Water Levels, 2015.

[27] NOAA, Tides and currents, (2017). https://tidesandcurrents.noaa.gov/.

[28] N.C. Nadal-Caraballo, J.A. Melby, V.M. Gonzalez, A.T. Cox, North Atlantic Coast Comprehensive Study — Coastal Storm Hazards from Virginia to Maine, U.S. Army Engineer Research and Development Center, Vicksburg, Mississippi, 2015.

[29] A.W. Niedoroda, D.T. Resio, G.R. Toro, D. Divoky, H.S. Das, C.W. Reed, Analysis of the coastal Mississippi storm surge hazard, Ocean Eng. 37 (2010) 82-90. doi:10.1016/j.oceaneng.2009.08.019. 
[30] M.D. Powell, T.A. Reinhold, Tropical Cyclone Destructive Potential by Integrated Kinetic 
Table 1: Historical TCs with recorded forerunner surges. Data source: (a) Garriott [1], (b)

422 Stewart [35], (c) Kennedy et al. [2], (d) NOAA [27], (e) Cline [36], and (f) Fanelli et al. [37].

423

\begin{tabular}{|c|c|c|}
\hline Tropical Cyclone & Area & $\begin{array}{c}\text { Forerunner Surge }(\mathrm{m}) \\
(\sim 12 \text { hours before landfall })\end{array}$ \\
\hline Unnamed, 1900 & Galveston, TX & $1.5^{(\mathrm{a})}$ \\
\hline Unnamed, 1915 & Galveston, TX & $2.1^{(\mathrm{b})}$ \\
\hline Ike, 2008 & Galveston, TX & $1.8-2.0^{(\mathrm{c})(\mathrm{d})}$ \\
\hline Unnamed, 1915 & Tampa, FL & $1.5^{(\mathrm{e})}$ \\
\hline Sandy, 2012 & Norfolk, VA & $1.0^{(\mathrm{f})}$ \\
\hline
\end{tabular}
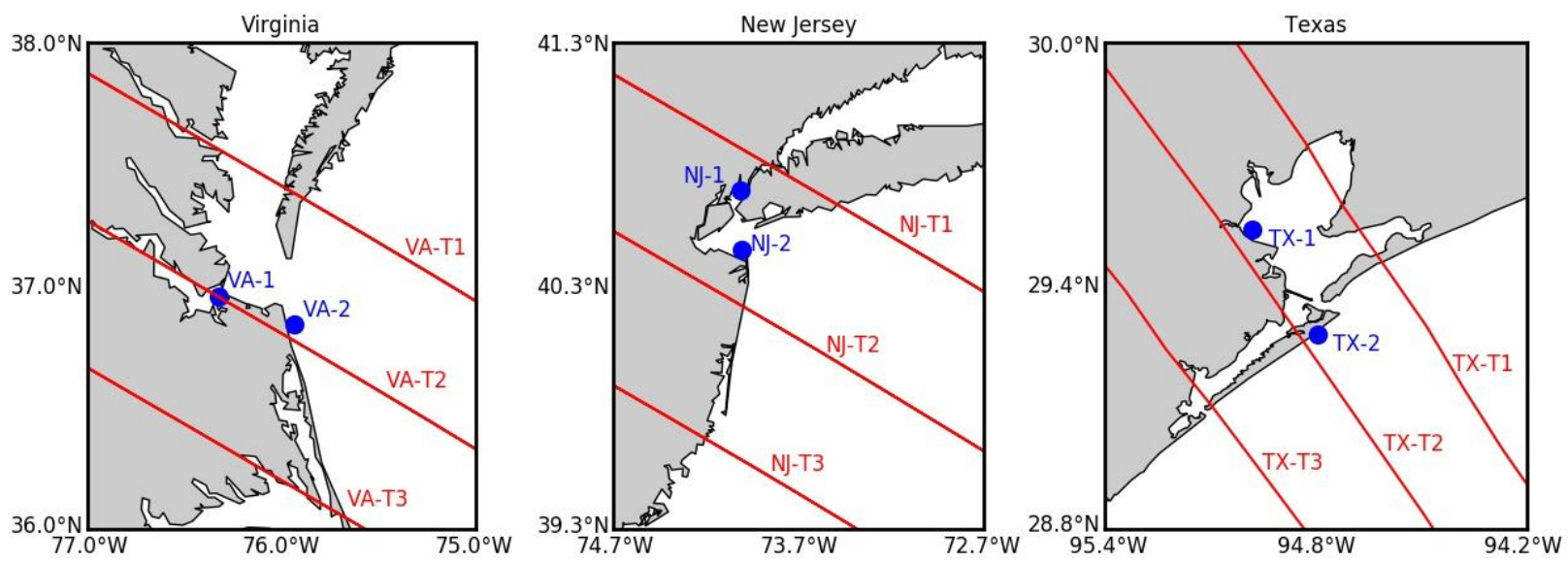

425 Figure 1: Maps of Virginia, New York/ New Jersey, and Texas coasts with synthetic TC tracks

426 and representative study locations. VA-1 and VA-2 are locations at Sewells Point and Virginia

427 Beach, respectively. TX-1 is within Galveston Bay and TX-2 is near Galveston. NJ-1 and NJ-2 


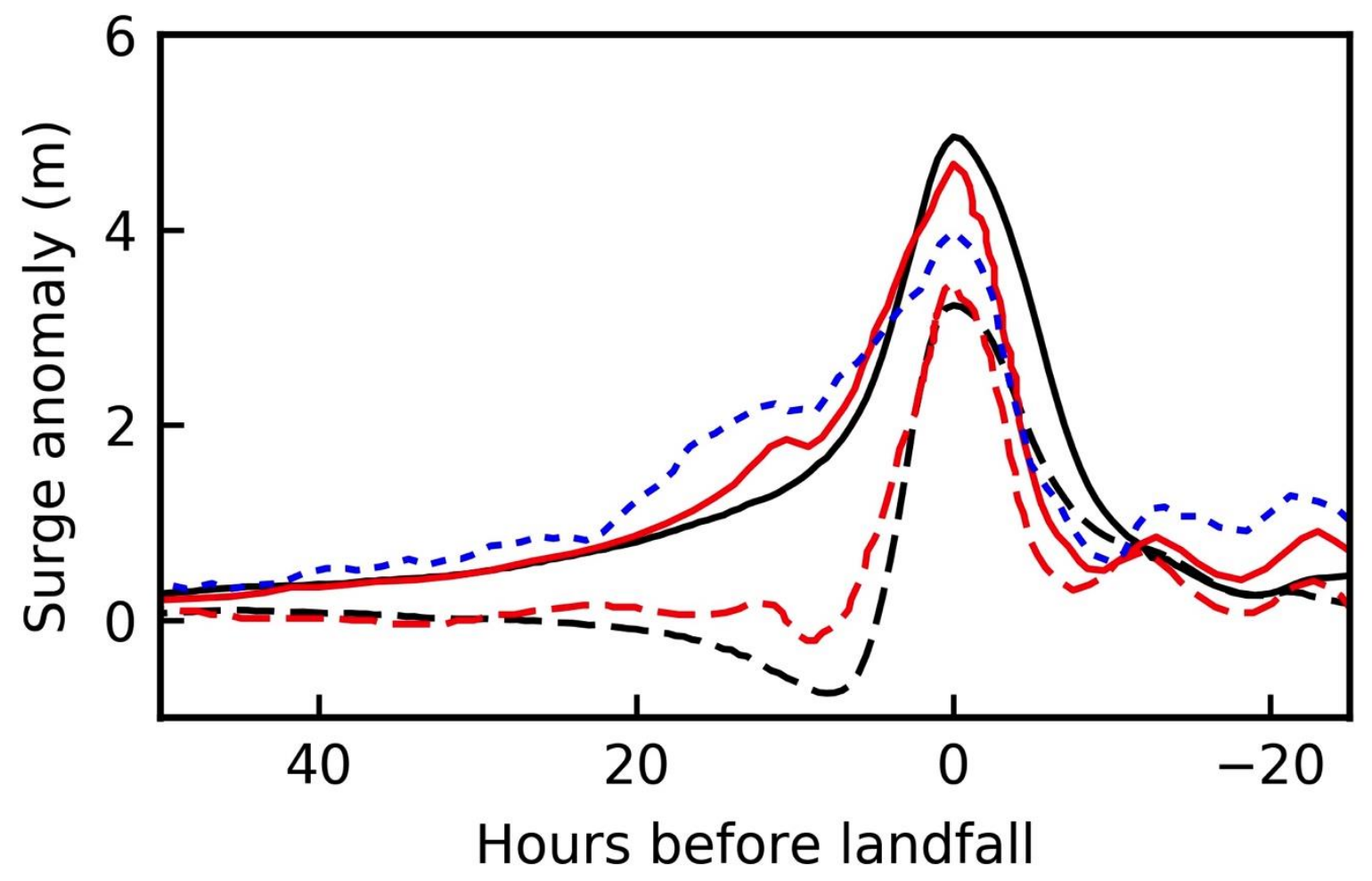

Figure 2. Surge time series validation for Hurricane Ike (2008) at location TX-2 in

431 Figure 1. Black lines: model results with parameterized wind (PBL); red lines: model results

432 with best reconstructed wind ( $\mathrm{H}^{*}$ wind); solid lines: model results with Coriollis force; dashed

433 lines: model results without Coriollis force; dotted line: observations. Dotted and dashed lines 

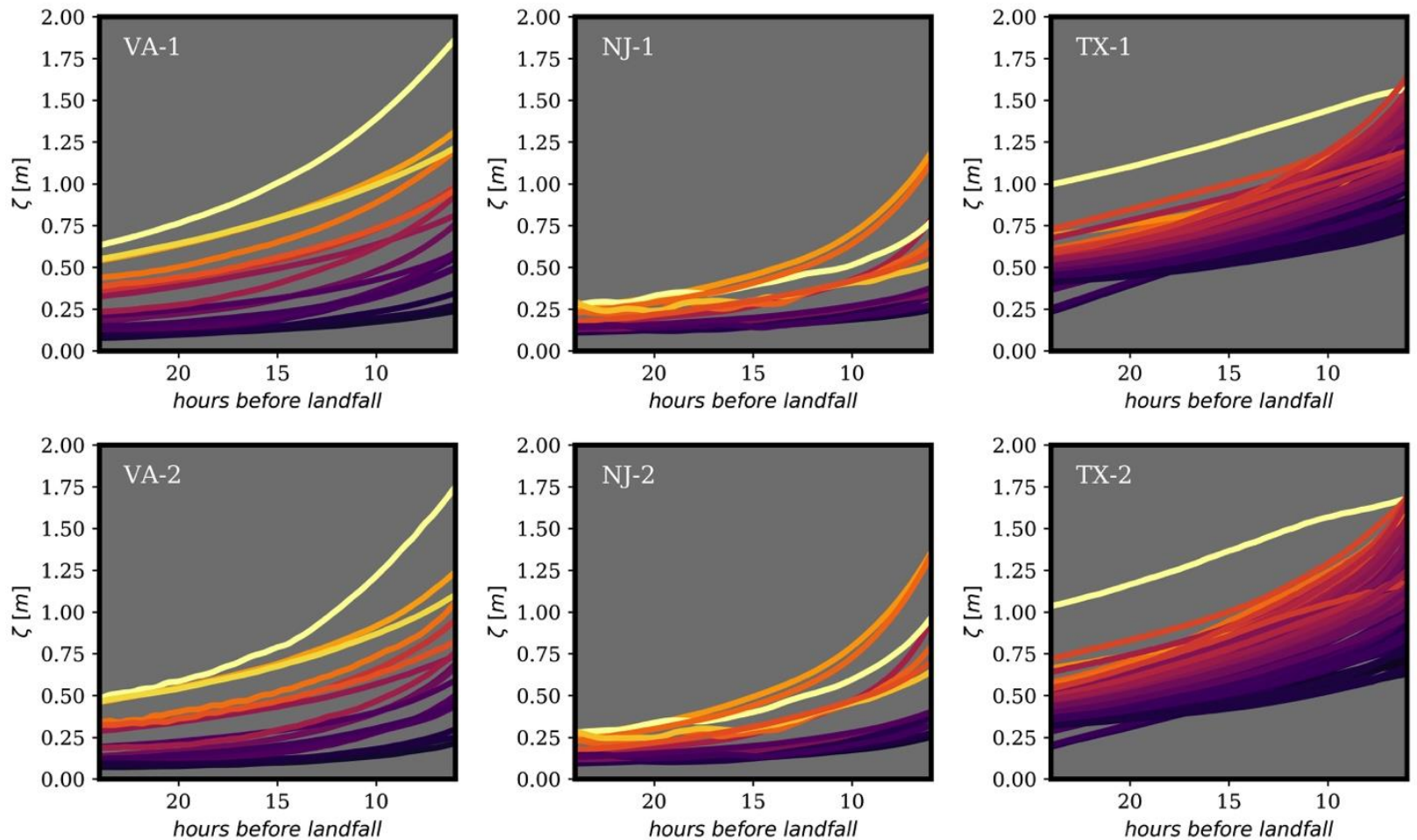

Figure 3: Surge time series of 19 simulations in Virginia, 18 simulations in New York/New

437 Jersey and 80 simulations in Texas. Timing is defined as hours before storm landfall. Plots are 

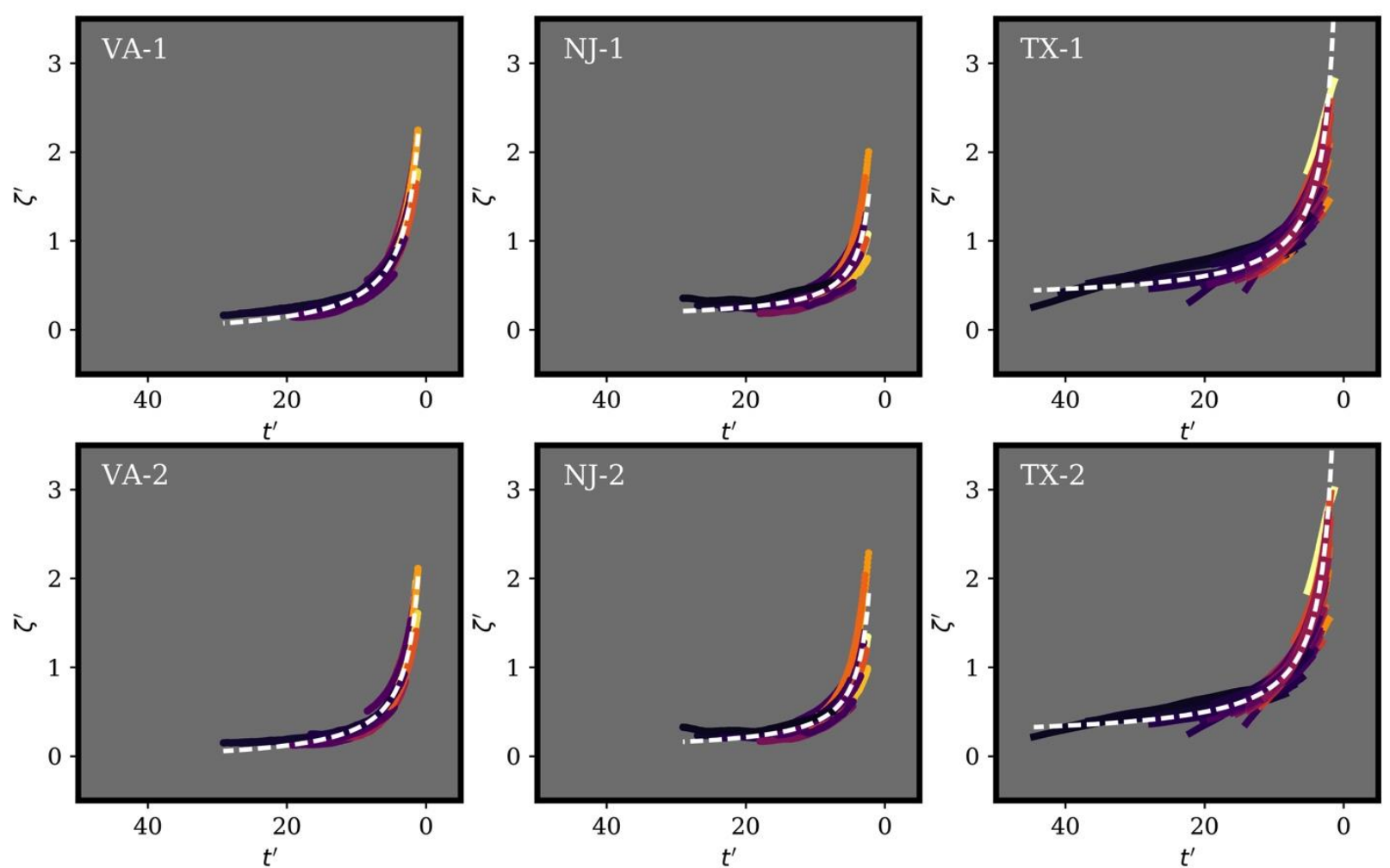

$440 \quad$ Figure 4: Plots of dimensionless surge $\left(\zeta^{\prime}\right)$ versus dimensionless time $\left(t^{\prime}\right)$ at representative $441 \quad$ locations. Plots are colorized by $(\Delta p)\left(\frac{R}{V_{f}}\right)$, where lighter colors represent larger values. The dashed white lines represent fitted hyperbolic curves. 
VA-2
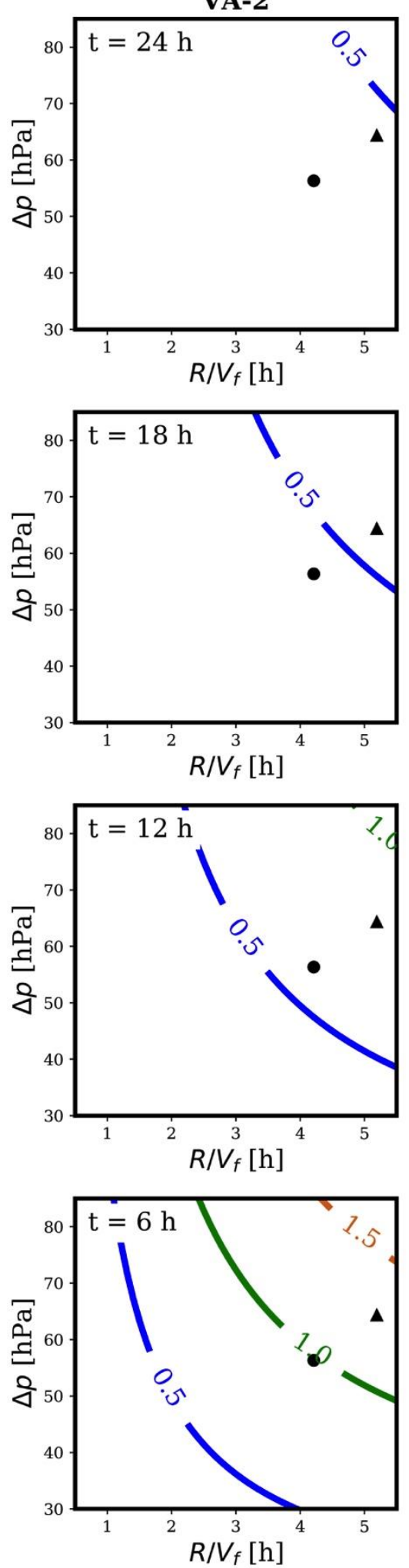

NJ-2
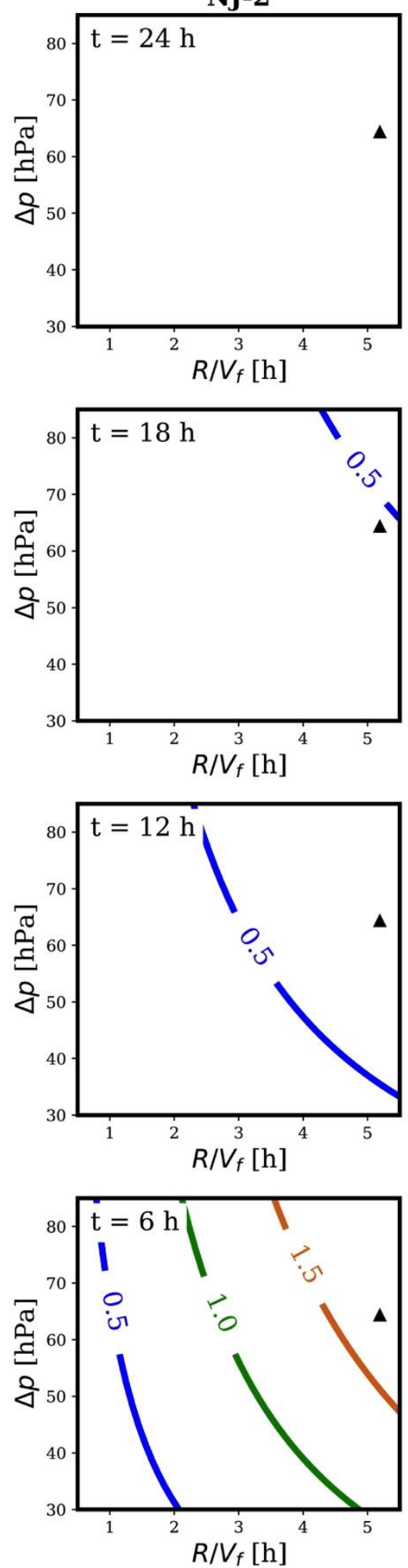

TX-2
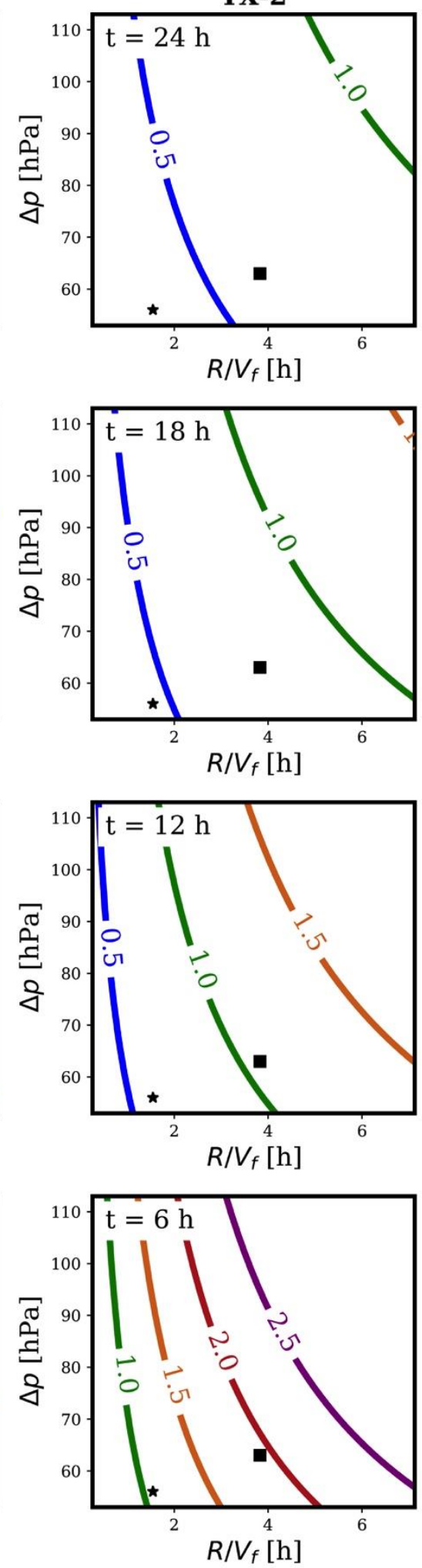
Figure 5: Deterministic forerunner surge forecasts at VA-2 (Virginia Beach) NJ-2

445 (Sandy Hook), and TX-2 (Galveston) at 24, 18, 12 and 6 hours before TC landfall, with

446 Hurricanes Isabel (2003, circles), Ike (2008, squares), Sandy (2012, triangles), and Harvey

447 (2017, stars) imposed. The 6-hr Sandy value at NJ-2 is extrapolated beyond the dimensionless 448 data limits. 

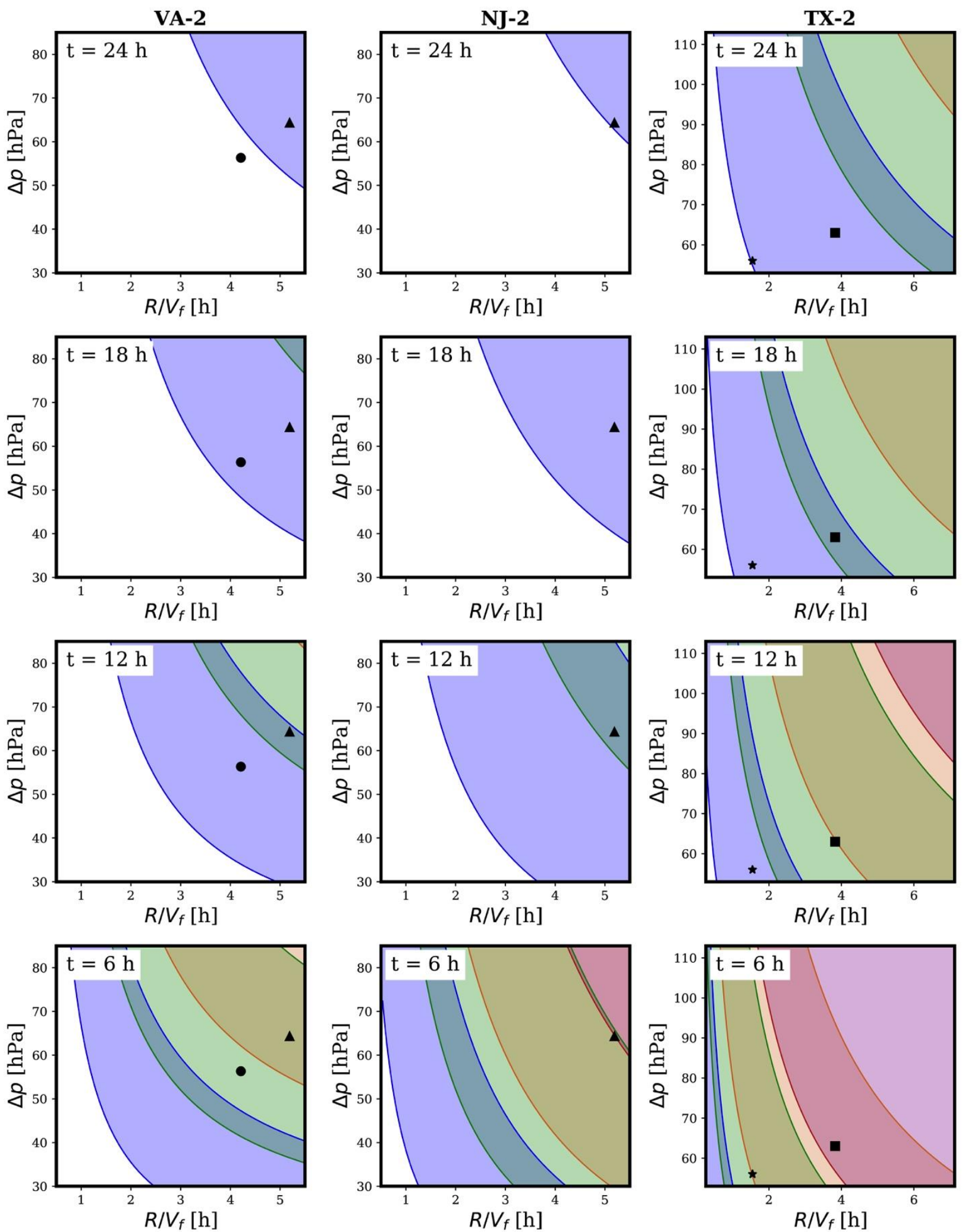
Figure 6: Forerunner surge forecasts with uncertainty bands at VA-2 (Virginia Beach)

452 NJ-2 (Sandy Hook), and TX-2 (Galveston) at 24, 18, 12 and 6 hours before TC landfall, with

453 Hurricanes Isabel (2003, circles), Ike (2008, squares), Sandy (2012, triangles), and Harvey

454 (2017, stars) imposed. Blue, green, orange and purple correspond to $0.5 \mathrm{~m}, 1.0 \mathrm{~m}, 1.5 \mathrm{~m}$, and 2.5

455 m respectively. The 6-hr Sandy value at NJ-2 is extrapolated beyond the dimensionless data

456 limits.

457 

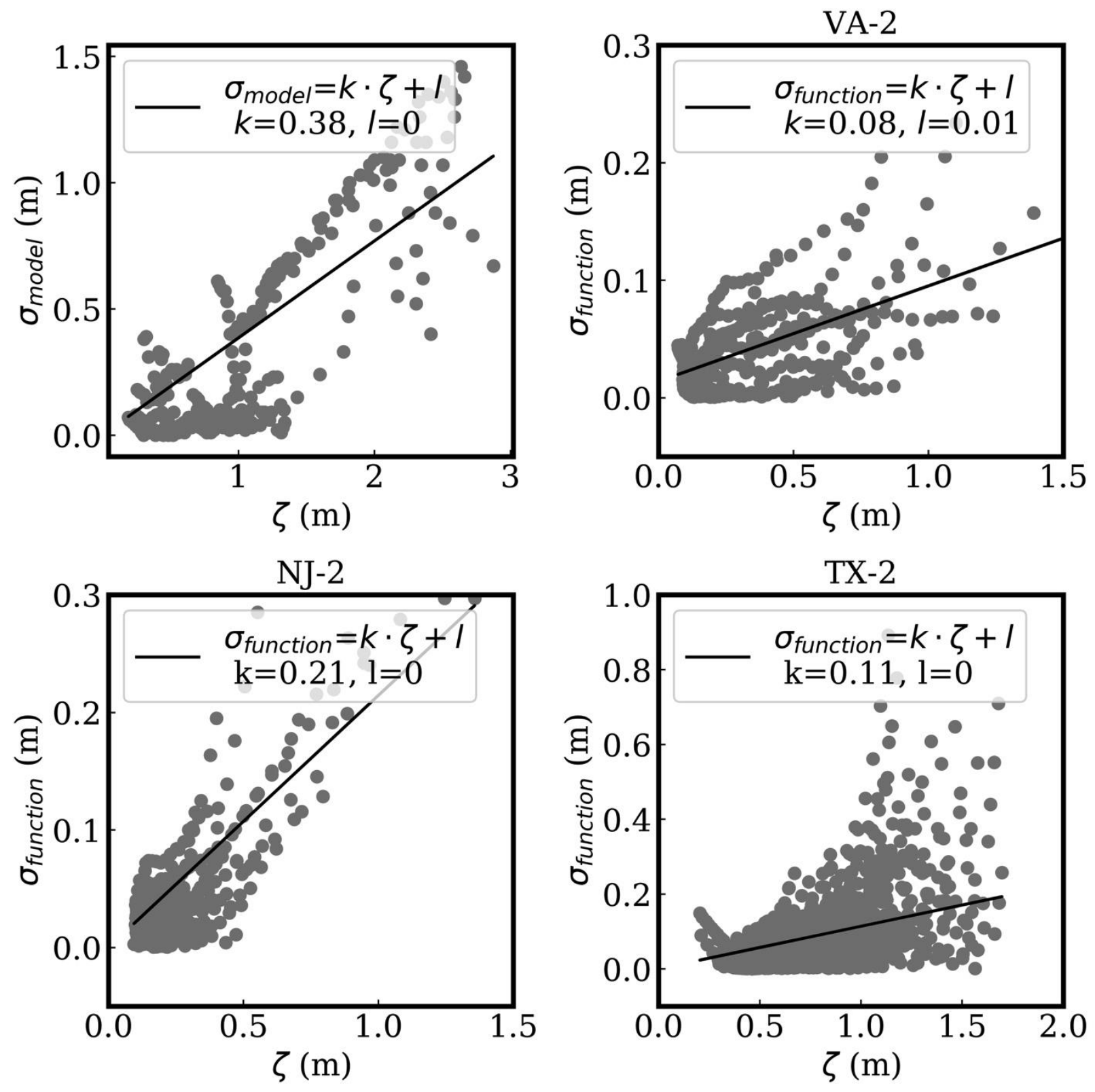
459 Figure 7. Surge magnitude prediction uncertainty quantification. $\sigma_{\text {model }}$ is calculated as

460 simulated surge standard deviation with respect to observations [27] due to wind

461 parameterization and hydrodynamic modeling based on ADCIRC-STWAVE and ADCIRC-

462 SWAN simulations at selected coastal locations. Shown are US Atlantic Hurricanes Sandy

463 (2012), Irene (2011), Isabel (2003), Gloria (1985), Josephine (1984) [26] and US Gulf of Mexico

464 Hurricanes Ike (2008), Katrina (2005), and Rita (2005) [25,26], for surge 24 to 6 hours before

465 landfall. $\sigma_{\text {function }}$ is calculated as error in surge prediction using Eqs. 2 and 3, represented by

466 standard deviation between curve fit and surge simulations at VA-2 (Virginia Beach) NJ-2

467 (Sandy Hook), and TX-2 (Galveston), for surge 24 to 6 hours before landfall. Each gray dot

468 represents surge values averaged over a 1-hour interval.

469
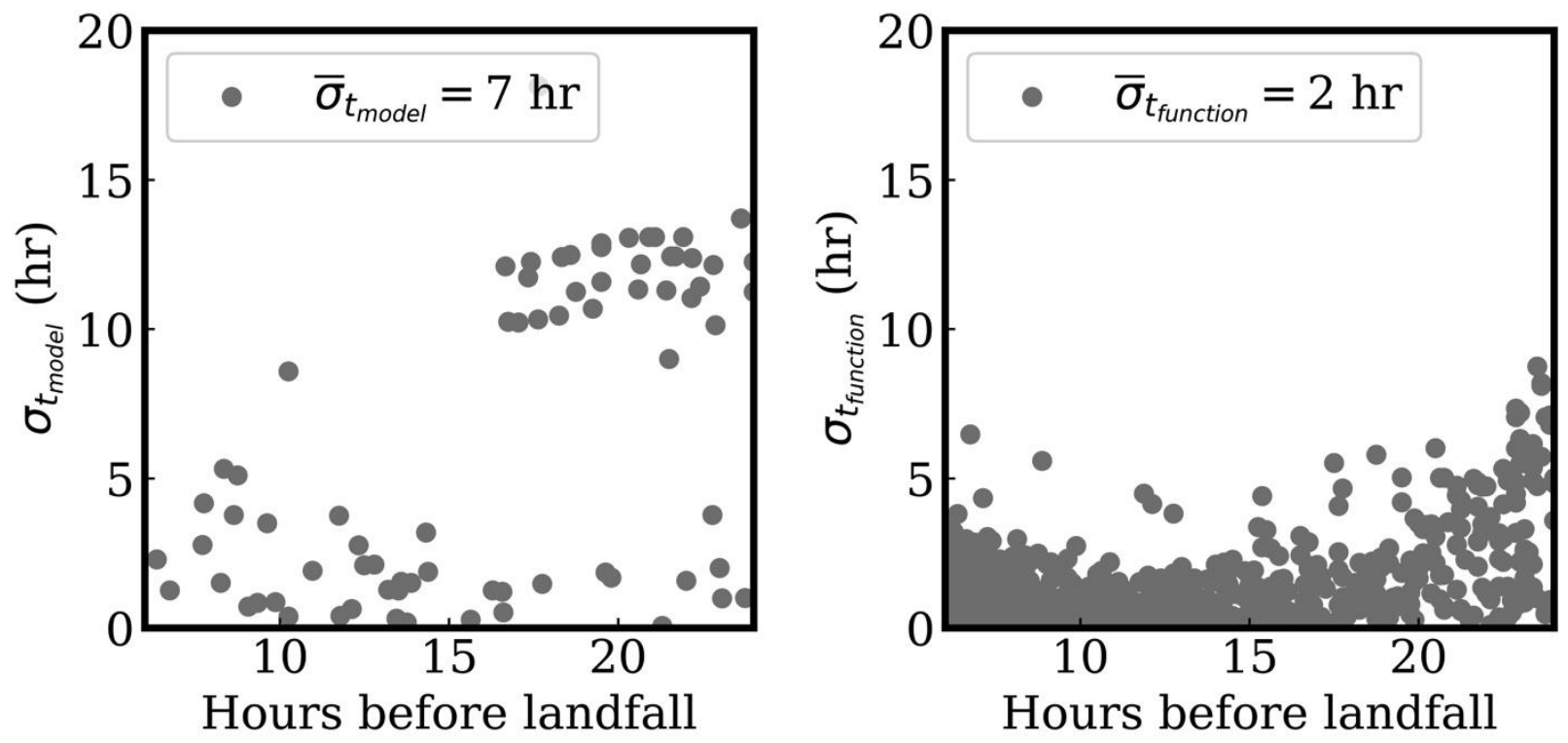

471

(a)

(b) 
472 Figure 8. Surge timing prediction uncertainty quantification. (a) Simulated timing standard

473 deviation [27] due to wind parameterization and hydrodynamic modeling based on ADCIRC-

474 STWAVE and ADCIRC-SWAN simulations at selected coastal locations. Shown are US

475 Atlantic Hurricanes Sandy (2012), Irene (2011), Isabel (2003), Gloria (1985), Josephine (1984)

476 [26] and US Gulf of Mexico Hurricanes Ike (2008), Katrina (2005), and Rita (2005) [25,26], for

477 the arrival of $0.3-\mathrm{m}$ to $2.0-\mathrm{m}$ surge. (b) Error in timing prediction when observed forerunner

478 surge is between 0.3-m to 2.0-m using Eqs. 2 and 3.

479 

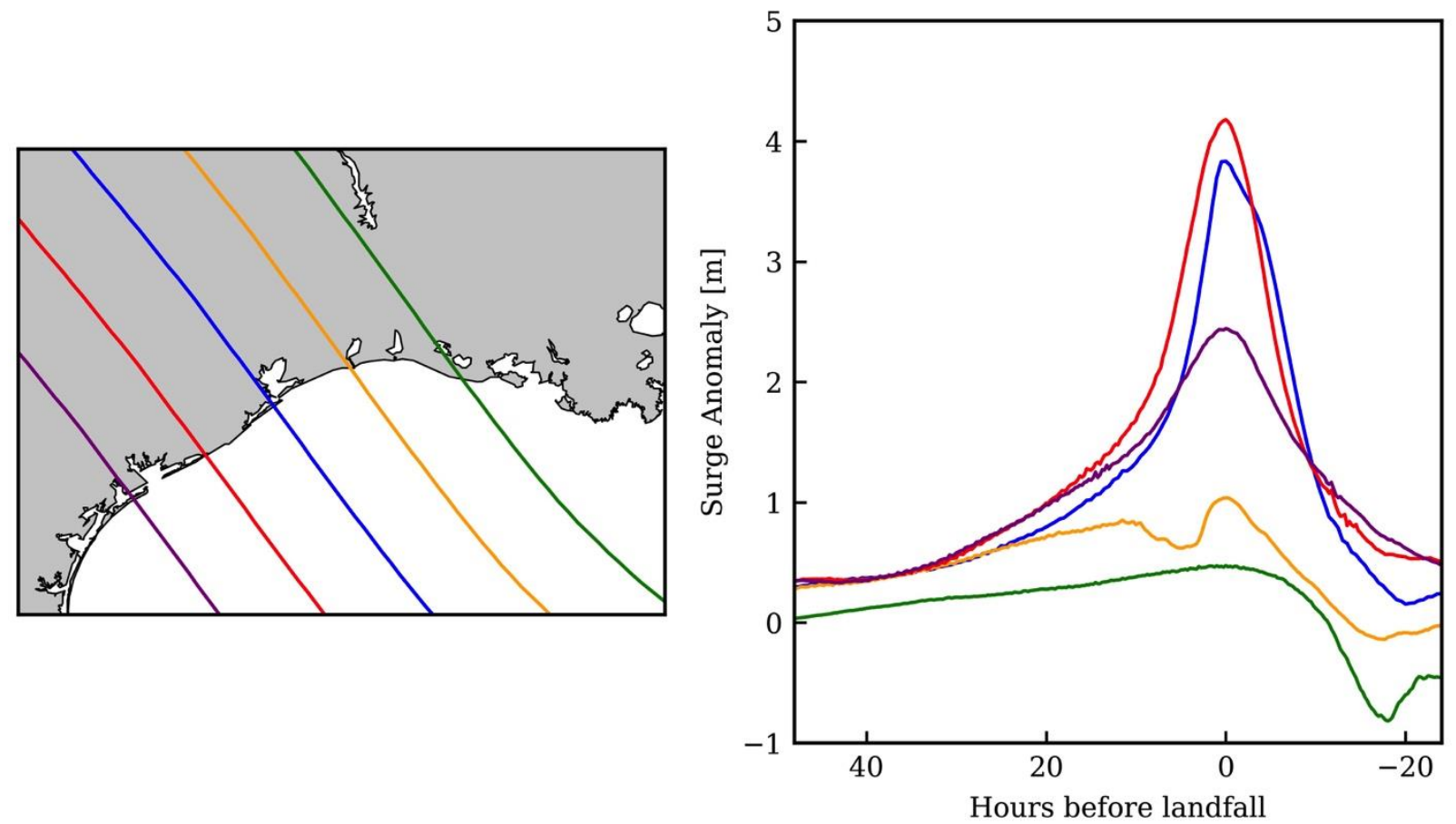

481

482 Figure A1. Tracks and surge time series for an Ike-like synthetic tropical cyclone that is shifting 100-km 483 or $200-\mathrm{km}$ to the south or north. 

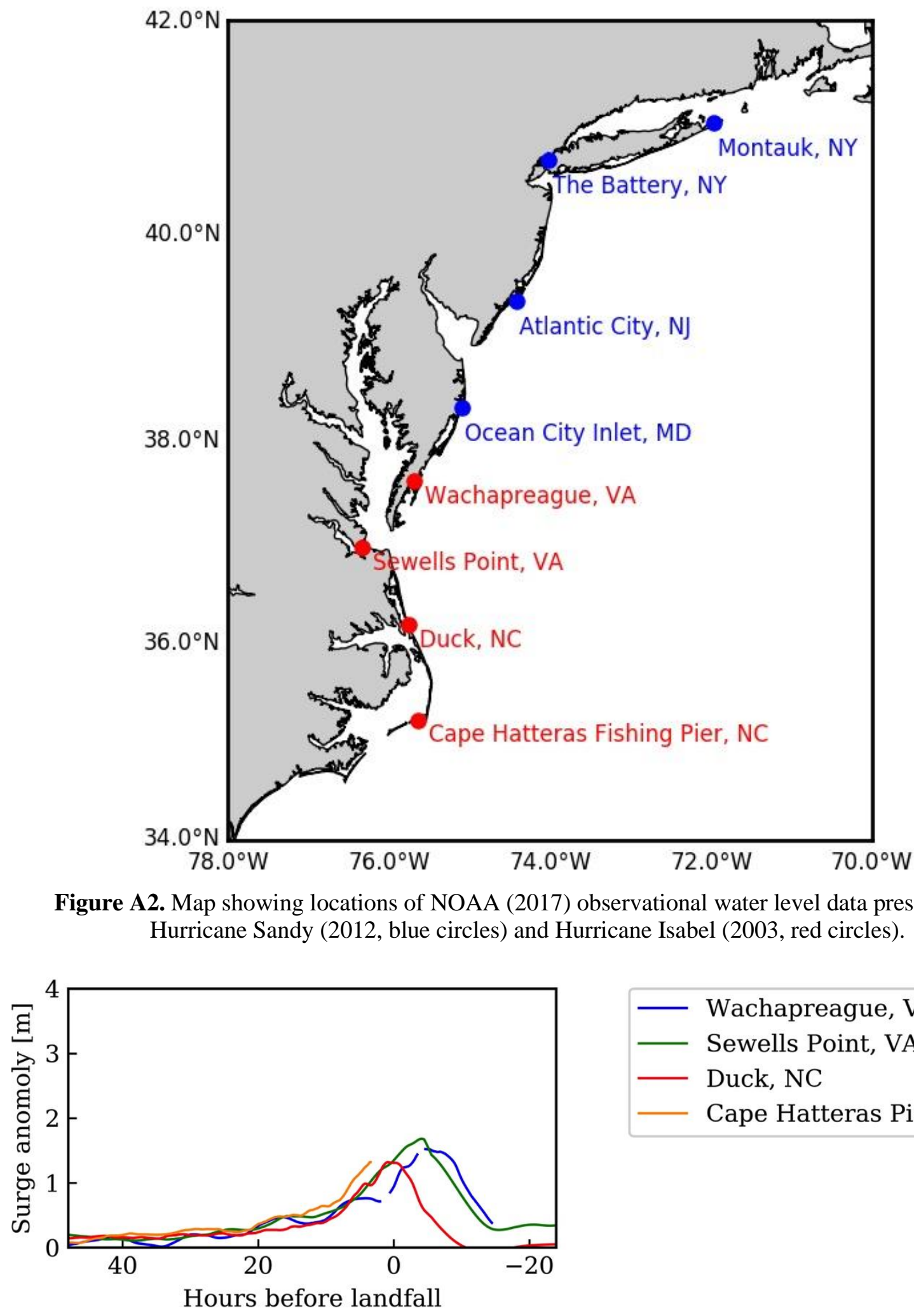

— Wachapreague, VA

— Sewells Point, VA

Figure A2. Map showing locations of NOAA (2017) observational water level data presented for Hurricane Sandy (2012, blue circles) and Hurricane Isabel (2003, red circles). 
Figure A3. Observed water level anomaly time series (NOAA 2017) for Hurricane Isabel (2003);

492 locations shown in Figure S3.

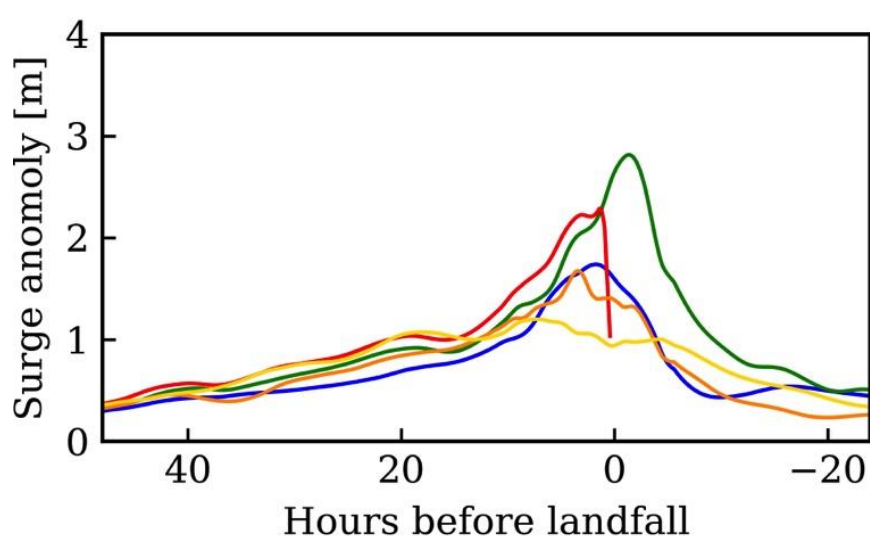

$$
\begin{array}{ll}
- & \text { Montauk, NY } \\
- & \text { The Battery, NY } \\
- & \text { Sandy Hook, NJ } \\
& \text { Atlantic City, NJ } \\
& \text { Ocean City Inlet, MD }
\end{array}
$$

Figure A4. Observed water level anomaly time series (NOAA 2017) for Hurricane Sandy (2012); 


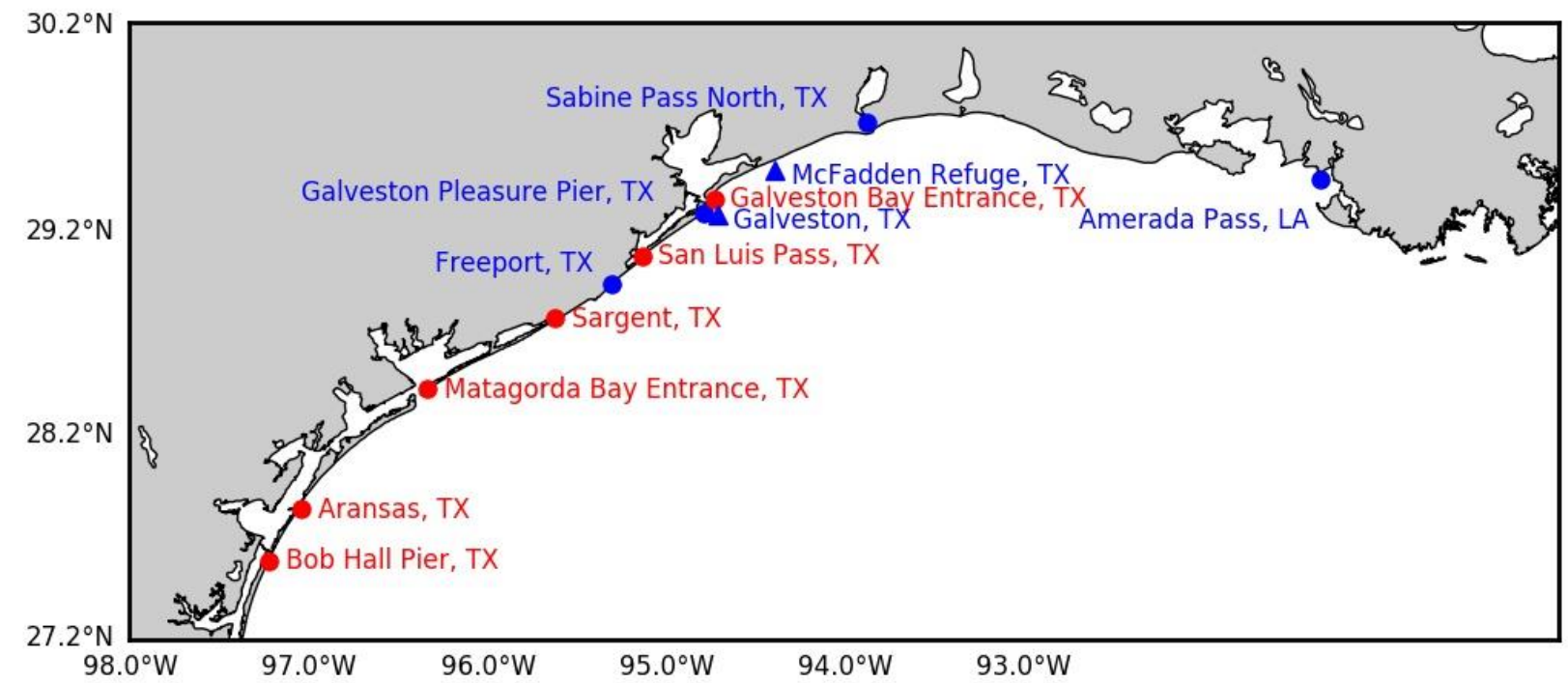

Figure A5. Map showing locations of observational water level data presented for Hurricane Ike (2008, blue circles and triangles) and Hurricane Harvey (2017, red circles). NOAA (2017) stations are circles and Kennedy et al. [2] stations are triangles.

502
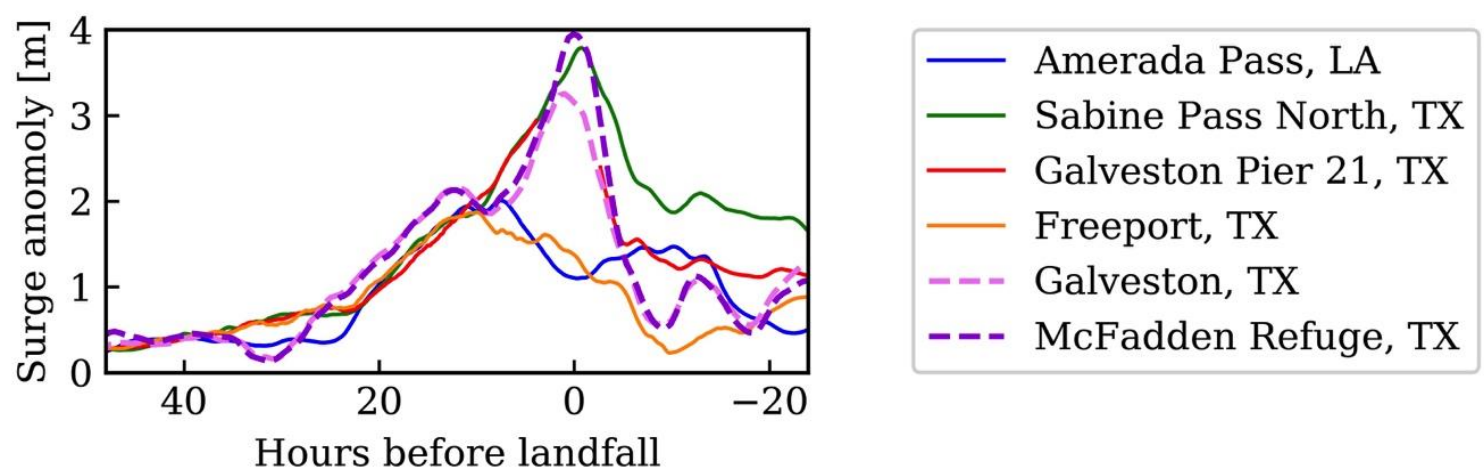

Figure A6. Observed water level anomaly time series (NOAA 2017 and Kennedy et al. 2011) for Hurricane Ike (2008); locations shown in Figure S6. 

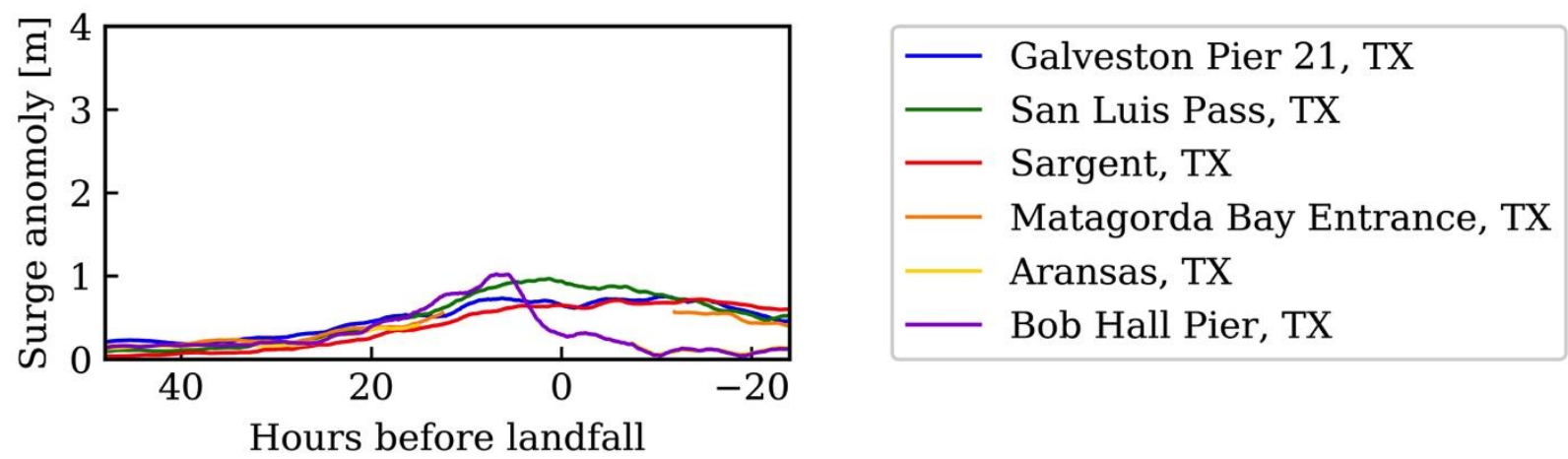

508

509

510

511

512

513

514

515

516

Figure A7. Observed water level anomaly time series (NOAA 2017) for Hurricane Harvey (2017); locations shown in Figure S6.

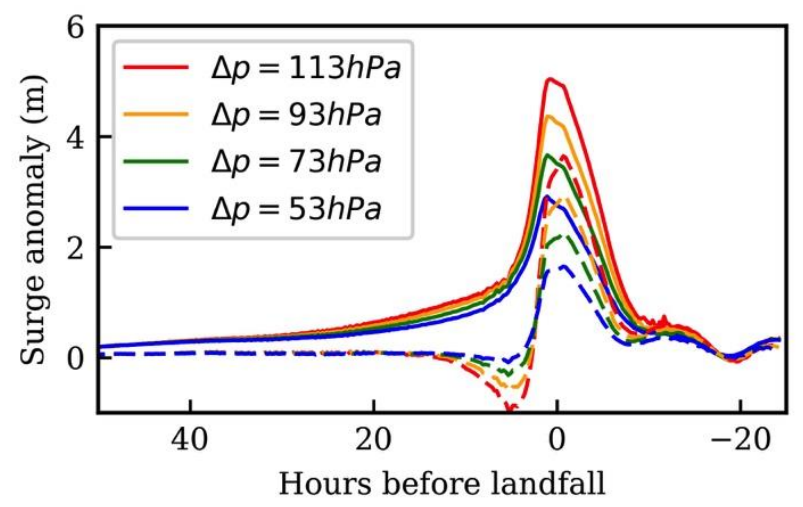

(a)

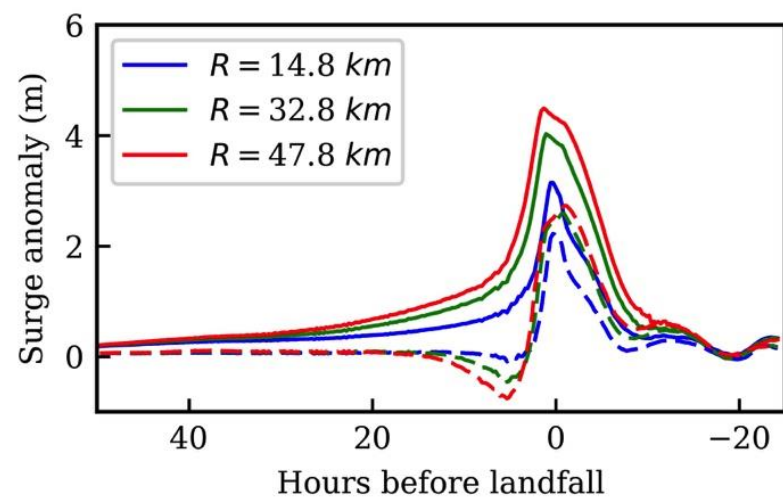

(b)

Figure A8. Simulated surge time series with (solid lines) and without (dashed lines) Coriolis forcing for tropical cyclones along track TX-T2 with a $5.66 \mathrm{~m} / \mathrm{s} \boldsymbol{V}_{\boldsymbol{f}}$ and (a) $32.8 \mathrm{~km} \boldsymbol{R}$, (b) $73 \mathrm{hPa} \Delta \boldsymbol{p}$. 
518 Table A1. Hurricane track parameters averaged between 6 to 24 hours before landfall. Data source: (a) 519 NHC [38], (b) Powell and Reinhold [30], (c) Nadal-Caraballo et al. [28], (d) Sebastian et al. [4], and (e) RAMMB [39].

521

522

\begin{tabular}{|c|c|c|c|}
\hline Hurricane & $\boldsymbol{\Delta p}(\mathbf{h P a})$ & $\boldsymbol{R}(\mathbf{k m})$ & $\boldsymbol{V}_{\boldsymbol{f}}(\mathbf{k m} / \mathbf{h})$ \\
\hline Isabel (2003) & $56^{(\mathrm{a})}$ & $87^{(\mathrm{b})}$ & $20^{(\mathrm{a})}$ \\
\hline Sandy (2012) & $65^{(\mathrm{a})}$ & $135^{(\mathrm{c})}$ & $26^{(\mathrm{a})}$ \\
\hline Ike (2008) & $63^{(\mathrm{a})}$ & $74^{(\mathrm{d})}$ & $18^{(\mathrm{a})}$ \\
\hline Harvey (2017) & $56^{(\mathrm{a})}$ & $26^{(\mathrm{e})}$ & $17^{(\mathrm{a})}$ \\
\hline
\end{tabular}

Table A2 Dimensionless curve fitting coefficients for Equation 3.

524

\begin{tabular}{|c|c|c|c|}
\hline \multirow{2}{*}{ Location } & \multicolumn{3}{|c|}{ Curve fitting coefficients } \\
\cline { 2 - 4 } & $\mathbf{a}$ & $\mathbf{b}$ & $\mathbf{c}$ \\
\hline VA-1 & 5.44 & 1.24 & -0.11 \\
\hline VA-2 & 4.36 & 0.96 & -0.09 \\
\hline NJ-1 & 2.70 & -0.38 & 0.11 \\
\hline NJ-2 & 3.21 & -0.49 & 0.05 \\
\hline TX-1 & 5.96 & 0.42 & 0.31 \\
\hline TX-2 & 6.30 & 0.24 & 0.18 \\
\hline
\end{tabular}

